УДК 66.021.3: 66.048.3

СОВЕРШЕНСТВОВАНИЕ КОНСТРУКЦИИ КОЛПАЧКОВОЙ ТАРЕЛКИ ДЛЯ РЕКТИФИКАЦИОННЫХ КОЛОНН

\title{
IMPROVING THE DESIGN OF CAP-TYPE PLATE FOR RECTIFICATION COLUMNS
}

\author{
В.Г. Афанасенко, Ю.Л. Юнусова, В.Ф. Хузиев, В.А. Яковлев
}

Уфимский государственный нефтяной технический университет, г. Уфа, Российская Федерация

\author{
Vitaliy G. Afanasenko, Julia L. Yunusova, Vilnar F. Khuziev, \\ Vitaliy A. Yakovlev
}

\section{Ufa State Petroleum Technological University, Ufa, Russian Federation \\ e-mail: nedra.ugntu@gmail.com}

\begin{abstract}
Аннотация. В целях развития нефтеперерабатывающей промышленности непрерывно ведется поиск решений, способствующих повышению интенсивности тепломассообменных процессов, что требует постоянного совершенствования основного оборудования, в частности аппаратов колонного типа. Наряду с распространенными способами интенсификации процессов тепломассообмена (увеличение удельной поверхности контакта фаз, повышение эффективности перемешивания, увеличение скорости относительного движения потоков, совершенствование способов осуществления контакта фаз и т.д.), эффективным способом решения подобной задачи является использование нестационарных режимов межфазного обмена, обеспечивающих достижение высоких мгновенных значений коэффициентов тепло- и массопередачи. При проведении опытов реализован принцип дискретно-
\end{abstract}


импульсных воздействий на обрабатываемые вещества, который заключается в том, что введенная в систему энергия концентрируется в локально разобщенных дискретных точках системы.

Контактные устройства являются основными элементами, влияющими на эффективность работы массообменных аппаратов колонного типа, поэтому применение принципа дискретно-импульсных воздействий целесообразно реализовывать локально на контактных устройствах.

Известно много конструкций контактных устройств, классифицируемых по различным признакам, обладающих отличными друг от друга эксплуатационными характеристиками. В данной работе представлена конструкция колпачковой массообменной тарелки, особенностью которой является использование термоэлектрических преобразователей, базирующихся на эффекте Пельтье, позволяющих вводить энергию в дискретные точки системы в виде дополнительного нагрева жидкой фазы и одновременного охлаждения паровой фазы, что является введением нестационарности по профилю температур в исследуемую систему. Приводятся описание конструкции разработанного контактного устройства, а также исследования, направленные на определение оптимального расположения термоэлектрических преобразователей, проведенные путем использования тепловизионной съемки эксперимента, измерением размеров зон термического воздействия. Получена конструкция, позволяющая осуществлять дополнительный нагрев стороны полотна тарелки, контактирующей непосредственно с жидкой фазой исследуемой жидкости, а также дополнительное охлаждение стороны полотна тарелки, контактирующей с газовой фазой. Площадь дополнительных нагрева и охлаждения относительно свободного полотна тарелки, согласно расчетам, составила 74,0 \% и 47,8 \% соответственно.

Abstract. For the purpose of oil refining industry development search of the solutions which are support increase of heat and mass transfer processes intensity entailing need of continuous main equipment improvement, in 
particular - column devices. Along with the common methods of heat and mass transfer processes intensification (increasing phase contact surface area, increasing the mixing efficiency, increasing the flows speed, improving the phase contact methods, etc.), an effective way to solve this problem is the use of non-stationary interfacial exchange modes, ensuring the achievement of heat high instantaneous values and mass transfer coefficients. To obtain nonstationary modes in the experiments which are described in this article, the energy discrete-pulse input principle on the processed substances is used, which consists in the fact that the energy injected into the system is concentrated in locally separated discrete points of the system.

Contact devices are the main elements that affect the efficiency of mass transfer column-type apparatus. So the application of the energy discrete-pulse input principle is advisable to implement locally on contact devices.

There are many designs of contact devices, classified according to different attributes, with different performance characteristics. This article presents the design of the cap-type mass transfer plate, a feature of which is the use of thermoelectric converters based on the Peltier effect, allowing to introduce energy into discrete points of the system in the form of additional heating of the liquid phase and simultaneous cooling of the vapor phase, that is the representation of non-stationary mode in the temperature profile in the studied system. The design description of the developed contact device, as well as studies aimed at determining the optimal location of thermoelectric converters, performed by using carried experiment thermal imaging, measuring the thermal impact zones size. The design allows for additional heating of the plate side being in contact directly with the liquid phase of the studied liquid, as well as additional cooling of the plate side being in contact with the gas phase. The additional heating and cooling area relative to the free plate sheet according to calculations was $74.0 \%$ and $47.8 \%$, respectively. 
Ключевые слова: массообменные процессы, контактное устройство, ректификационные колонны, дискретно-импульсный ввод энергии, эффект Пельтье

Key words: mass transfer processes, contact device, rectification columns, energy discrete-pulse input, Peltier effect

\section{Введение}

Ректификационные колонны, предназначенные для разделения смесей с разной температурой кипения, широко используются в нефтеперерабатывающей промышленности, поэтому от их эффективности зависят материальные, энергетические и трудовые затраты, качество нефтепродуктов и показатели по отбору, глубина переработки и др. [1-3].

В химической, нефтехимической, пищевой, газовой промышленности теплоэнергетике теплообменные и тепломассообменные аппараты применяются не только как самостоятельные аппараты, но и как составные устройства сложной технологической цепочки, поэтому важным фактором интенсификации различных процессов является повышение эффективности аппаратов наименьшей производительности.

Массообменные процессы на границе раздела фаз протекают иначе, чем в объеме реагирующей среды, в связи с тем, что переходный слой между фазами обладает мультифрактальными свойствами в распределении энергетических и геометрических параметров [4]. Существует множество способов совершенствования контакта фаз, один из них - импульсное воздействие на обрабатываемые вещества, в частности использование температурных неоднородностей в гетерогенных средах [5-12]. 


\section{Конструкция массообменной тарелки с термоэлектирическими преобразователями}

В процессе разработки контактных устройств для массообменных аппаратов одной из основных задач является повышение эффективности процесса ректификации [13-15].

Указанная задача в данной работе решается за счет температурного воздействия на паровую и жидкую фазу разделяемого потока путем создания массообменной тарелки, содержащей паровые патрубки, колпачки и сливные устройства, в основании которой установлены плоские элементы термоэлектрических преобразователей, принцип действия которых основан на эффекте Пельтье, - элементы Пельтье (ЭП). Принцип работы ЭП заключается в возникновении разности температур при протекании электрического тока [16-19].

На рисунке 1 представлен общий вид колпачковой тарелки с термоэлектрическими преобразователями.

Колпачковая тарелка представляет собой два соединенных листа металла: нижний 5 и верхний 6, между которыми находятся термоэлектрические преобразователи Пельтье 7, также конструкция содержит паровые патрубки 1, колпачки 2, сливные устройства 3.

На рисунке 2 представлен термоэлектрический преобразователь, установленный между листов металла основания тарелки.

Принцип действия устройства следующий: при пропускании электрического тока через элементы термоэлектрических преобразователей 7 одна сторона элемента нагревается, a другая охлаждается. Установка таких элементов между двух слоев металла, образующих массообменную тарелку, позволит дополнительно подогревать верхний би охлаждать нижний 5 листы.

Рассмотрим принцип действия разработанного контактного устройства с точки зрения массообменного процесса, происходящего в ректификационной колонне: в процессе ректификации поток паровой 
фазы, обогащенный низкокипящим компонентом, подводится к нижней (охлаждаемой) части 5 поверхности тарелки, и при непосредственном контакте с ней происходит отвод тепла из газовой фазы.

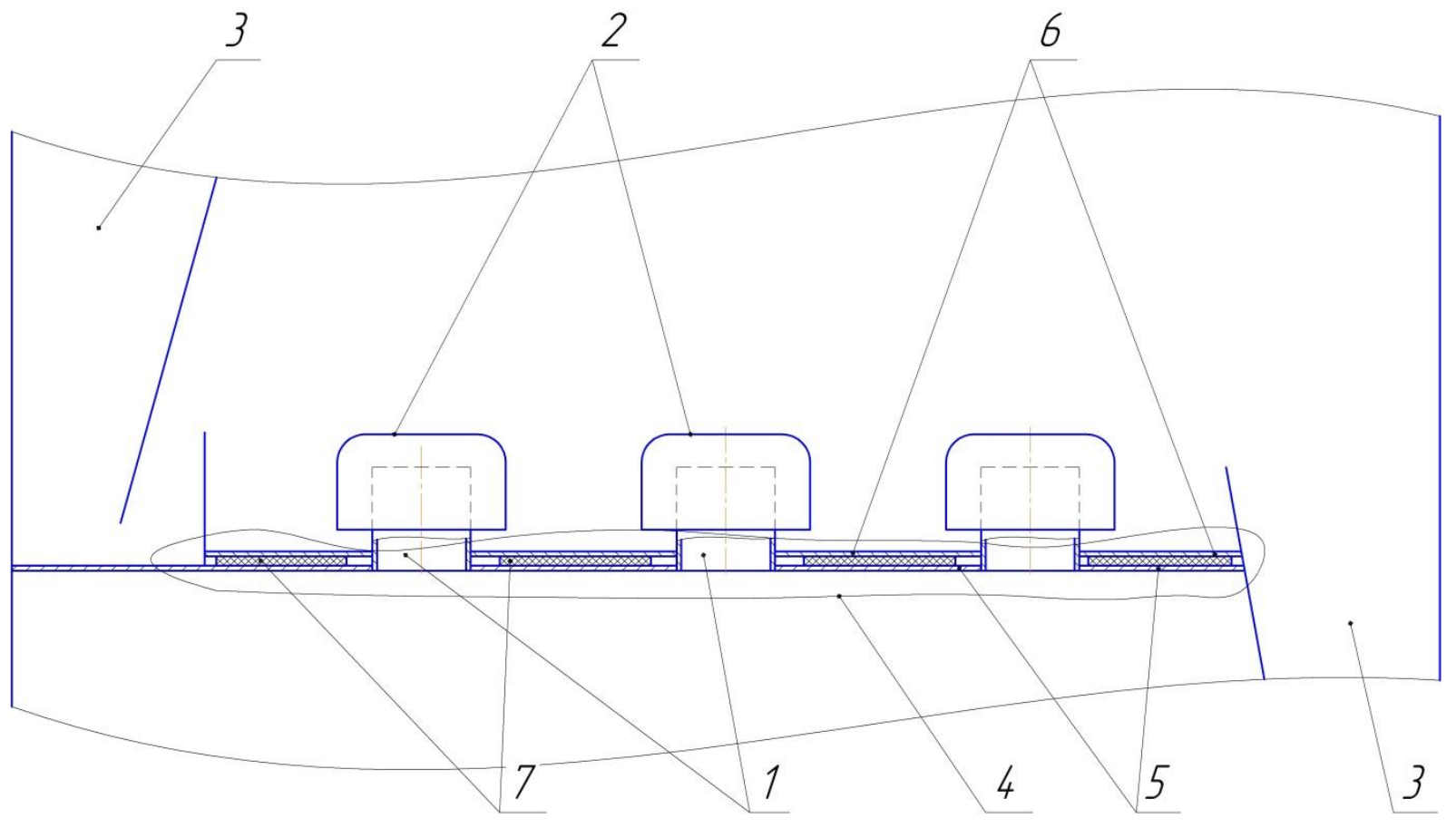

1 - паровые патрубки; 2 - колпачки; 3 - сливные устройства;

4 - полотно тарелки; 5 - нижний лист металла; 6 - верхний лист металла;

7 - термоэлектрические преобразователи

Рисунок 1. Колпачковая тарелка с термоэлектрическими преобразователями

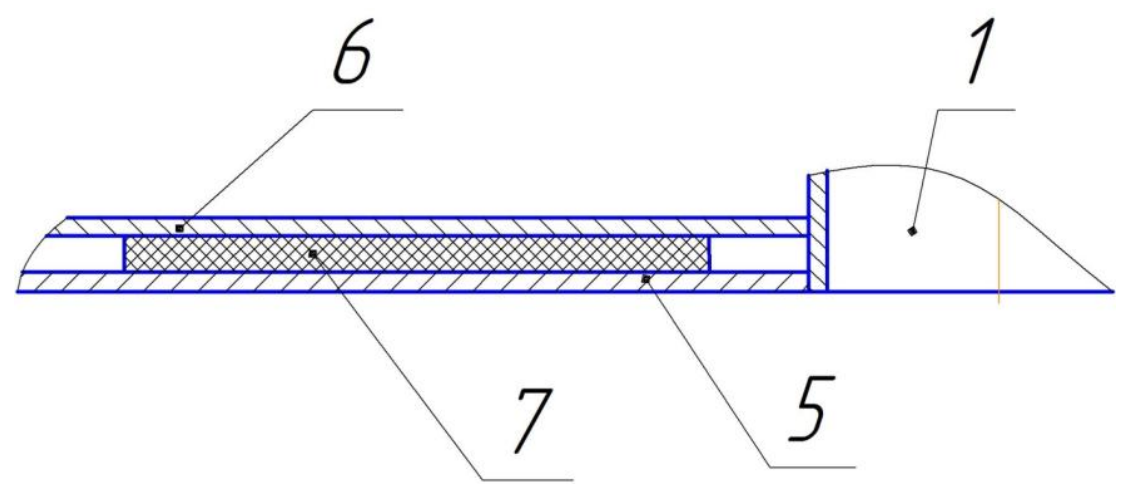

1 - патрубки; 5 - нижний лист металла; 6 - верхний лист металла;

7 - термоэлектрический преобразователь

Рисунок 2. Термоэлектрический преобразователь, установленный в тарелке 
Этот процесс приводит к частичной конденсации высококипящего компонента разделяемой смеси, повышая эффективность ректификации. Далее паровая фаза проходит через патрубки 1, закреплённые на тарелке, и, разворачиваясь при контакте с колпачком 2, барботируется через слой жидкой фазы, который находится на верхней (нагреваемой) поверхности тарелки.

На втором этапе реализуется традиционный этап тепломассообменного процесса при непосредственном контакте фаз.

Поток жидкой фазы, состоящий преимущественно из высококипящих компонентов смеси, движется горизонтально по верхней поверхности основания тарелки, обтекая колпачки 2, от одного сливного устройства 3 к другому. Дополнительное тепло, отдаваемое верхней поверхностью 6 основания тарелки 4 жидкой фазе, увеличивает количество испаренного низкокипящего компонента, что повышает эффективность разделения смеси [20].

\section{Исследование эффективности теплоотдачи полотна тарелки со встроенным элементом Пельтье}

Для наибольшей эффективности работы контактного устройства необходимо обеспечить оптимальное расположение термоэлементов между листами основания тарелки, для этого необходимо определить, какая площадь поверхности полотна тарелки нагревается, а какая охлаждается при использовании стандартного модуля элемента Пельтье.

С целью определения оптимально шага расположения термоэлементов Пельтье был сконструирован стенд, представленный на рисунке 3.

С его помощью производились измерения температуры нагрева и охлаждения листового металла при контакте его с термопреобразователем Пельтье. Для регистрации показаний использовалась тепловизионная съемка. 


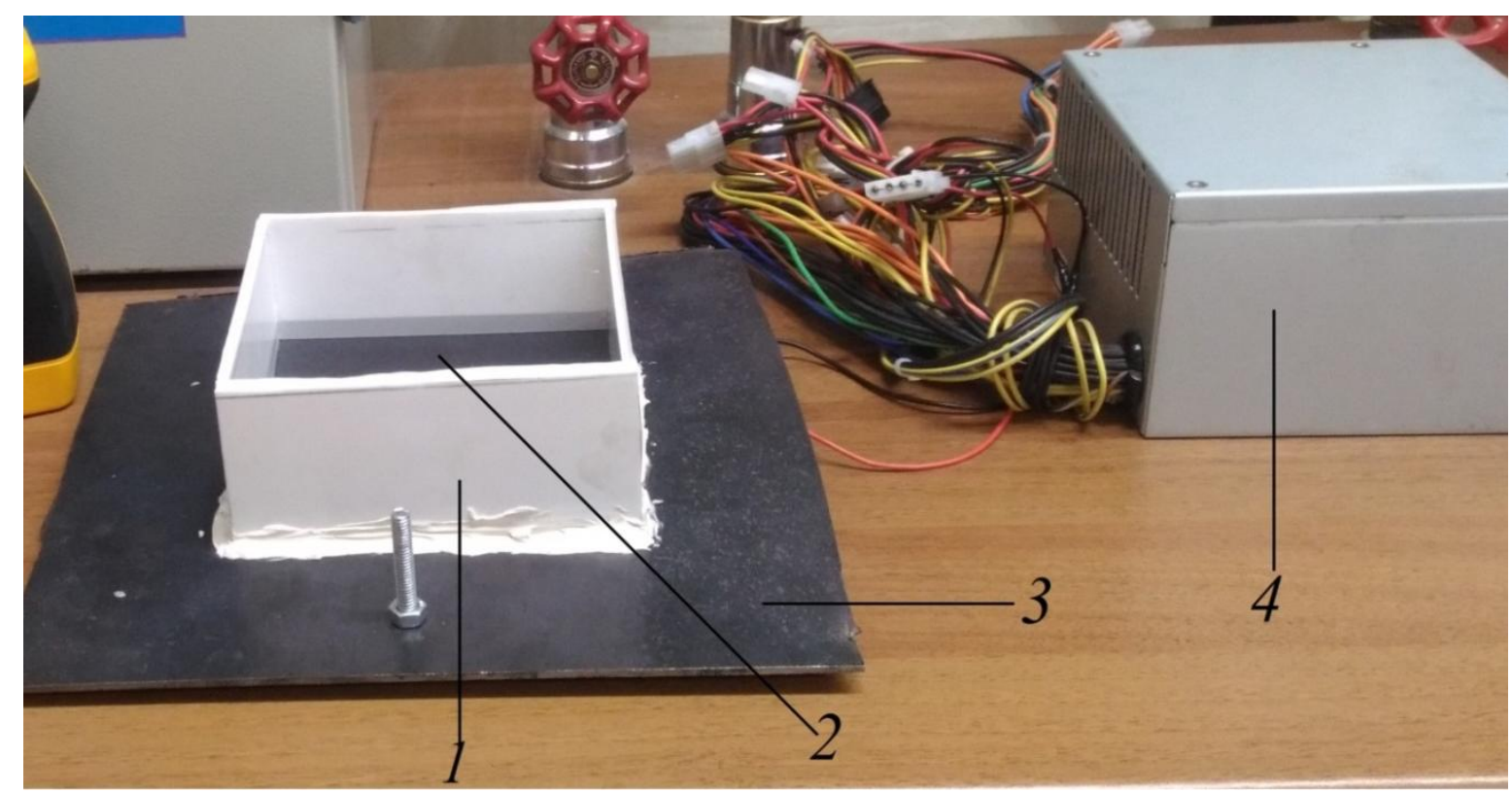

1 - открытая емкость с водой; 2 - место установки ЭП между двумя листами стали; 3 - листовая сталь толщиной 2 мм; 4 - генератор постоянного электрического тока

Рисунок 3. Фотография экспериментальной сборки с охлаждением

Исследования проводились в два этапа:

1) без жидкости на поверхности тарелки;

2) с имитацией жидкой фазы на поверхности тарелки.

Жидкая фаза способствует отводу тепла от верхней поверхности полотна тарелки в месте расположения термоэлемента.

Отвод тепла осуществлялся с помощью полимерной емкости, наполненной водой температурой равной начальной температуре остальных элементов системы (уровень воды устанавливался аналогичным уровню жидкости в лабораторной колонне для исследования процесса ректификации). Изменения температуры регистрировались при помощи тепловизора Ti55 IR Flexcam. Для удобства интерпретации результатов используются следующие обозначения: «низ» - охлаждаемая сторона исследуемого материала, «верх» - нагреваемая сторона. Начальная температура исследуемого материала составляет $20^{\circ} \mathrm{C}$.

Тепловизионная съемка проводилась в течение 5 мин, регистрация изображения осуществлялась с интервалом 0,5 мин для четырех случаев: 
1. «верх» без охлаждения (рисунок 4);

2. «верх» с охлаждением (рисунок 5);

3. «низ» без охлаждения (рисунок 6);

4. «низ» с охлаждением (рисунок 7).

На рисунках 4-7 показаны фото эксперимента для 0,5 мин, 1,0 мин, 3,0 мин, 4,0 мин, 4,5 мин, 5,0 мин работы термоэлектрического преобразователя с указанием максимальной (для нагреваемой стороны) и минимальной (для охлаждаемой стороны) температуры исследуемого материала.

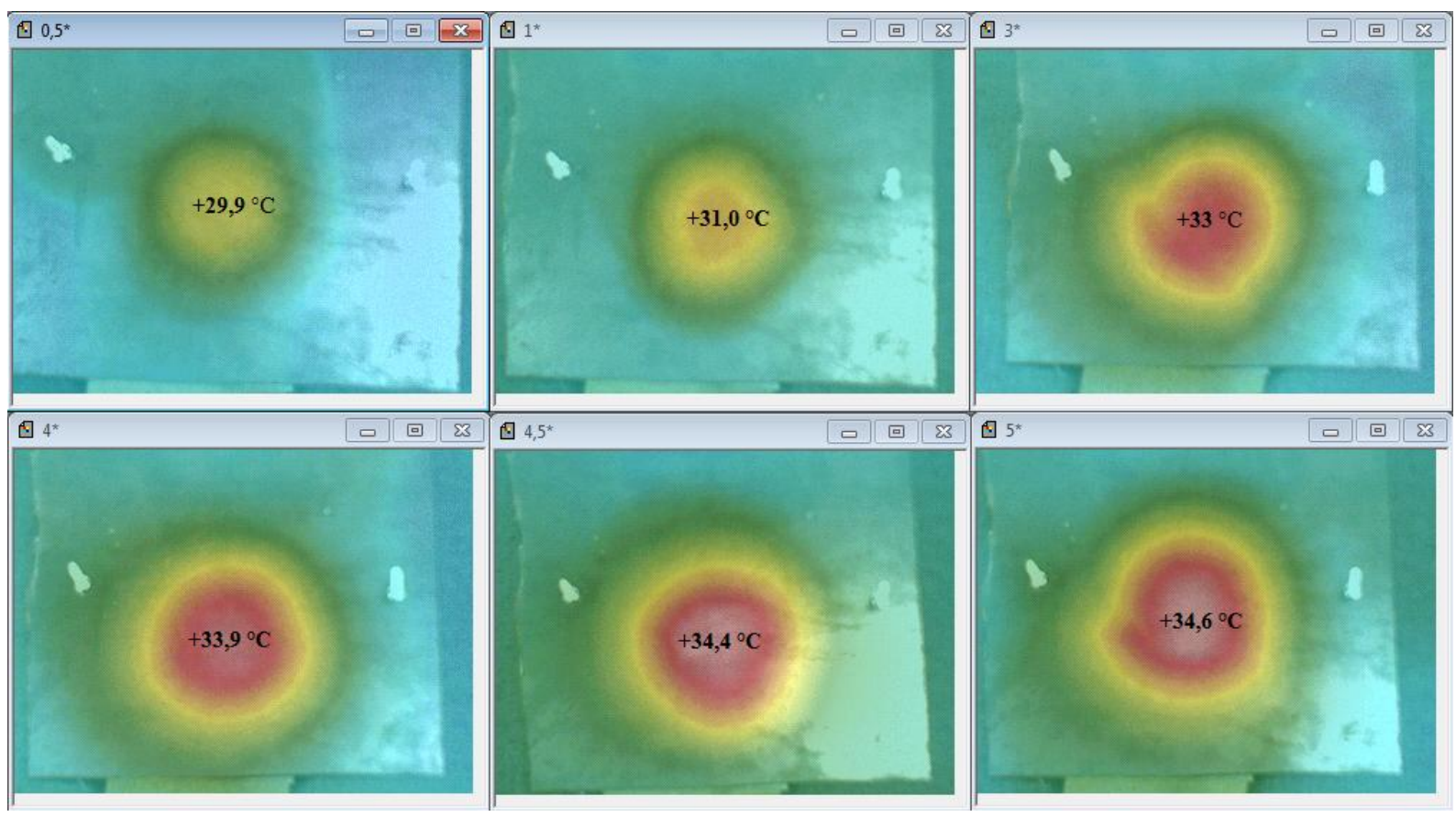

Рисунок 4. Тепловизионная съемка «верха» без охлаждения (0,5 мин; 1,0 мин; 3,0 мин; 4,0 мин; 4,5 мин; 5,0 мин) 


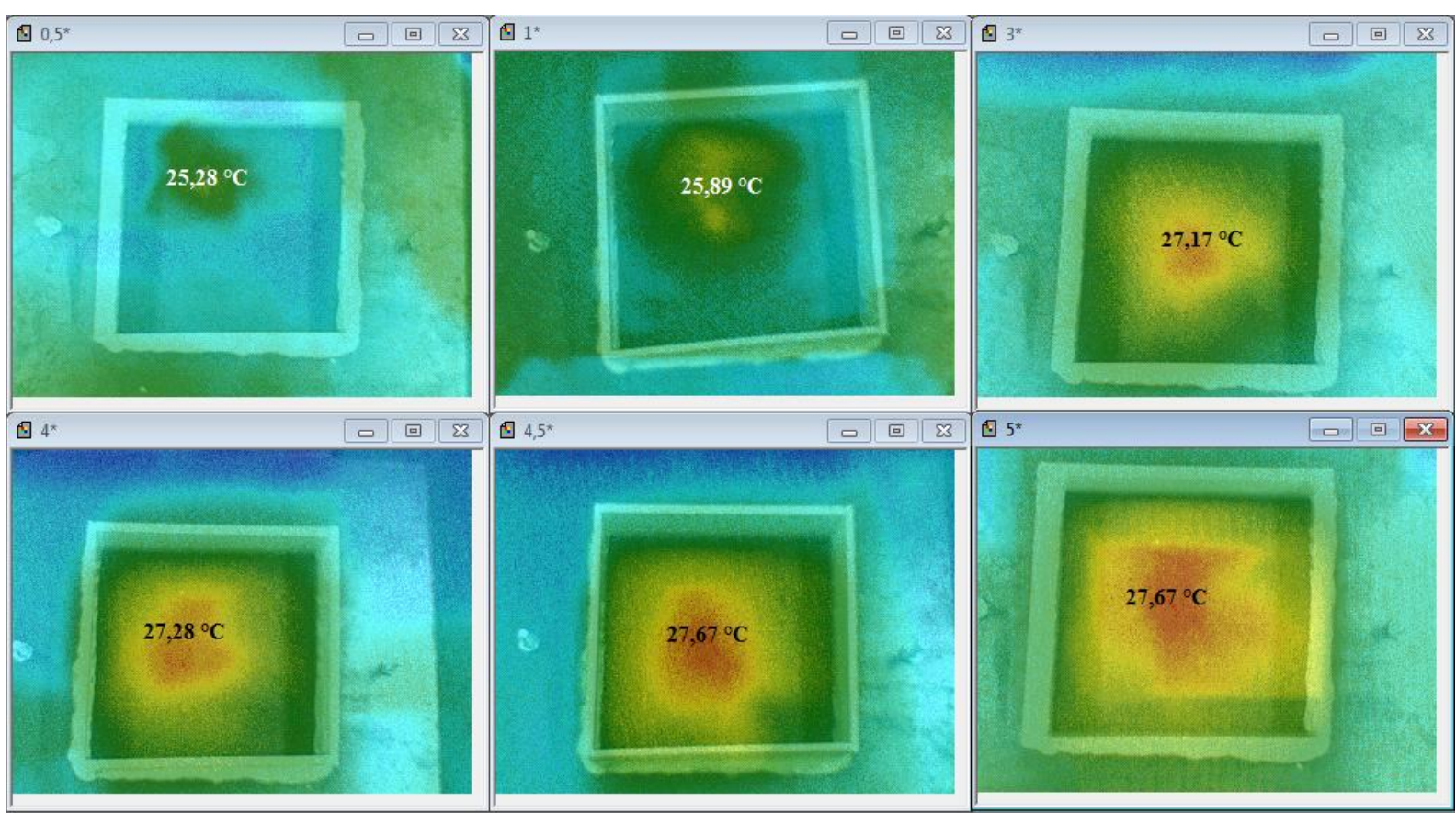

Рисунок 5. Тепловизионная съемка «верха» с охлаждением (0,5 мин; 1,0 мин; 3,0 мин; 4,0 мин; 4,5 мин; 5,0 мин)

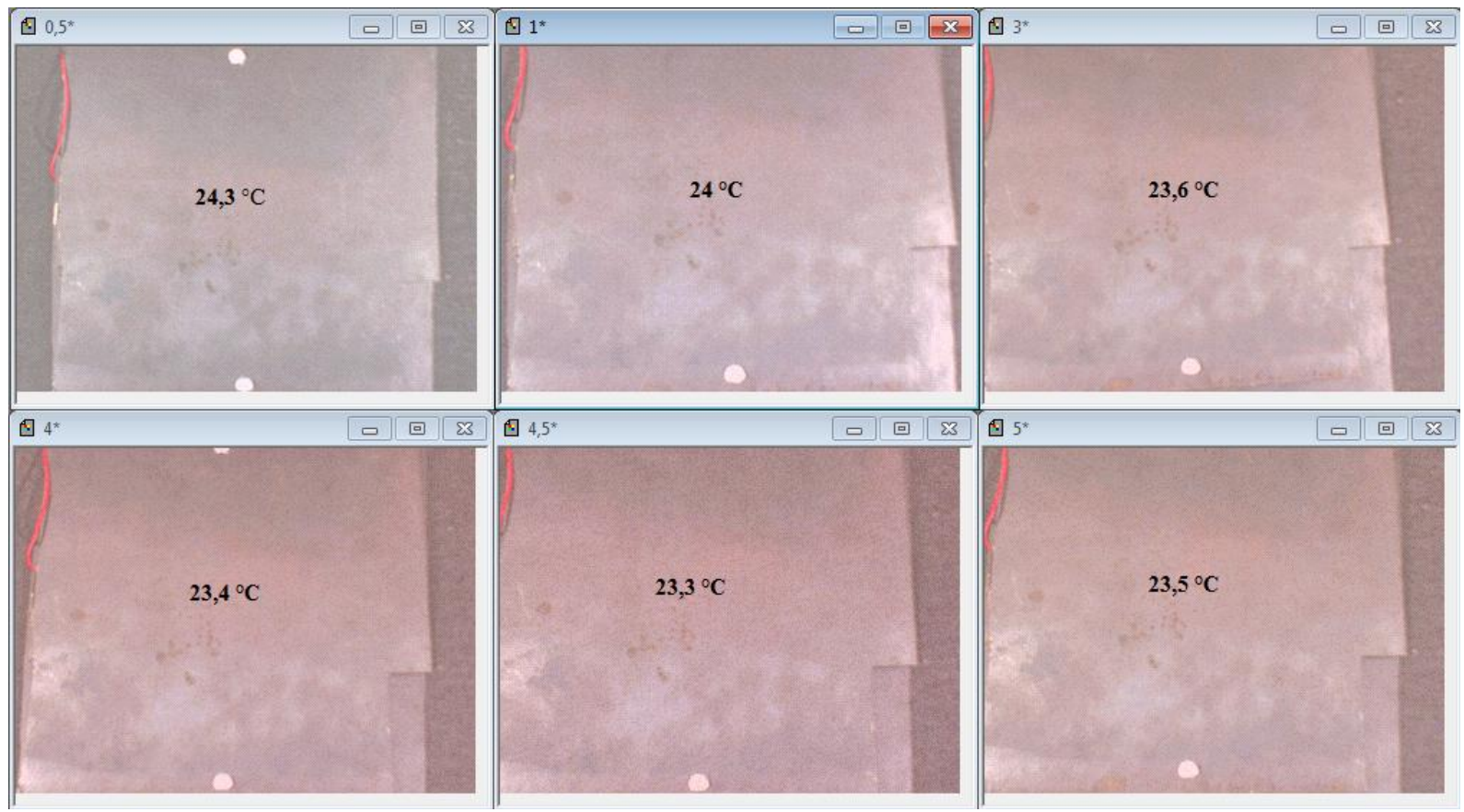

Рисунок 6. Тепловизионная съемка «низа» без охлаждения (0,5 мин; 1,0 мин; 3,0 мин; 4,0 мин; 4,5 мин; 5,0 мин) 


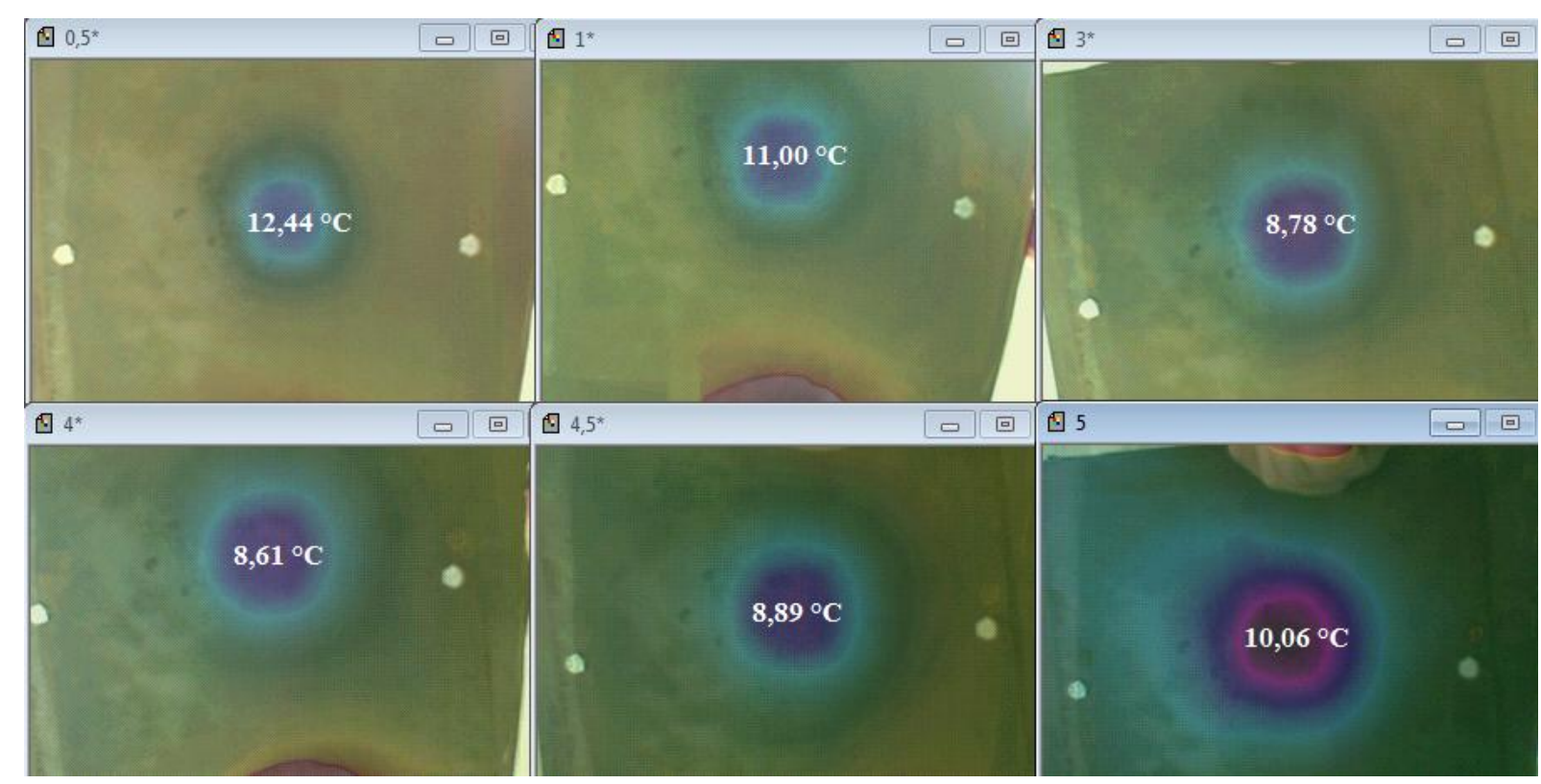

Рисунок 7. Тепловизионная съемка «низа» с охлаждением (0,5 мин; 1,0 мин; 3,0 мин; 4,0 мин; 4,5 мин; 5,0 мин)

Инфракрасное излучение тепловизора проникает через объем воды и регистрирует температуру металла, контактирующего с термоэлементом. В связи с этим дополнительно проводились измерения температуры воды термометром стеклянным ТН7 с диапазоном измерений от $0{ }^{\circ} \mathrm{C}$ до $360{ }^{\circ} \mathrm{C}$, получены данные, приведенные в таблице 1:

Таблица 1. Результаты измерения температур в ходе испытания

\begin{tabular}{|l|c|c|c|c|}
\hline $\begin{array}{c}\text { № } \\
\text { п/п }\end{array}$ & Время, мин & $\begin{array}{c}\text { Температура } \\
\text { воды }\end{array}$ & $\begin{array}{c}\text { Температура } \\
\text { металла (верх) }\end{array}$ & $\begin{array}{c}\text { Температура } \\
\text { металла (низ })\end{array}$ \\
\hline \multicolumn{4}{|c|}{ Уровень воды- 1 см (200 мл) } & \\
\hline 1. & 0 & 21,0 & 21,00 & 21,00 \\
\hline 2. & 1,0 & 22,0 & 25,89 & 11,00 \\
\hline 3. & 2,0 & 23,0 & 26,28 & 9,11 \\
\hline 4. & 3,0 & 23,5 & 27,17 & 8,78 \\
\hline 5. & 4,0 & 24,0 & 27,28 & 8,61 \\
\hline 6. & 4,5 & 24,3 & 27,67 & 8,89 \\
\hline 7. & 5,0 & 24,5 & 27,67 & 10,06 \\
\hline
\end{tabular}


Из таблицы 1 следует, что при достижении времени 4,5 мин количество отводимой энергии с верхней поверхности основания начинает уменьшаться. В связи с этим в данной работе при оценке шага расположения термоэлементов учитывался размер теплового пятна нагревающейся части, зарегистрированный при 4,5 мин от начала испытания.

Для анализа распространения тепловой энергии термоэлемента были взяты данные по размеру теплового пятна при работе термоэлектрического преобразования в течение 4,5 мин, т.к. при дальнейшем проведении эксперимента без отвода тепла охлаждающая сторона теряет эффективность и начинается постепенный нагрев контактирующего с ней материала. Это связано с тем, что происходит частичная передача тепла от горячей стороны термоэлемента к холодной. При достижении температуры кипения жидкости эффективность работы холодной стороны начнет увеличиваться.

Экспериментально определены площади нагрева и охлаждения поверхности основания тарелки, изготовленной из листового стального проката толщиной 2 мм. Средний диаметр поверхности нагрева составил 134 мм. Средний диаметр поверхности с пониженной температурой составил 76 мм.

При определении оптимального шага расположения стандартных термоэлементов учитывались следующие параметры:

1. размеры используемого в ходе эксперимента термоэлектрического преобразователя - $\quad$ элемента Пельтье $\quad$ SP1848 27145 SA $(40$ × 40 × 4 мM);

2. размер области термического воздействия, зарегистрированной при 4,5 мин от начала испытания;

3. параметры колпачковой тарелки согласно отраслевому стандарту [21]. 
Согласно отраслевому стандарту [21], тарелка колпачковая неразборная, для колонных аппаратов диаметром 400 мм имеет параметры согласно таблице 2.

Таблица 2. Параметры колпачковых тарелок

\begin{tabular}{|c|c|c|c|c|c|}
\hline $\begin{array}{c}\text { Диаметр } \\
\text { колонны } \\
\mathrm{D}\end{array}$ & $\begin{array}{c}\text { Диаметр } \\
\text { основания } \\
\text { тарелки } \\
\mathrm{D} 1\end{array}$ & $\begin{array}{c}\text { Диаметр } \\
\text { колпачка d }\end{array}$ & $\begin{array}{c}\text { Размер скоб } \\
\text { крепежных } \\
\text { колпачков, мм }\end{array}$ & $\begin{array}{c}\text { Диаметр } \\
\text { колпачка d }\end{array}$ & $\begin{array}{c}\text { Кол-во } \\
\text { колпачков } \\
\text { на тарелке } \\
\text { n, шт. }\end{array}$ \\
\hline 400 & 380 & 60 & 36 & 60 & 7 \\
\hline
\end{tabular}

Определение оптимального места расположения элементов Пельтье проводилось со следующими допущениями (рисунок 8):

а) при расчетах учитывался не диаметр колпачков, а размер скоб крепежных, т.к. возможность расположения термоэлементов регламентируется положением скоб;

б) расположением болтов и шпилек пренебрегли.

Коэффициент термического воздействия нагреваемой поверхности $\left(K_{t 1}\right)$ вычислялся по формуле:

$$
K_{t 1}=\frac{s_{t 1}}{S_{0}} \cdot 100 \%,
$$

где $S_{0}$ - свободная поверхность тарелки;

$S_{t 1}$ - площадь нагрева.

Коэффициент термического воздействия охлаждаемой поверхности $\left(K_{t 2}\right)$ вычислялся по формуле:

$$
K_{t 2}=\frac{S_{t 2}}{S_{0}} \cdot 100 \%
$$

где $S_{0}$ - свободная поверхность тарелки;

$S_{t 2}$ - площадь охлаждения.

Полученные данные отражены в таблице 3: 


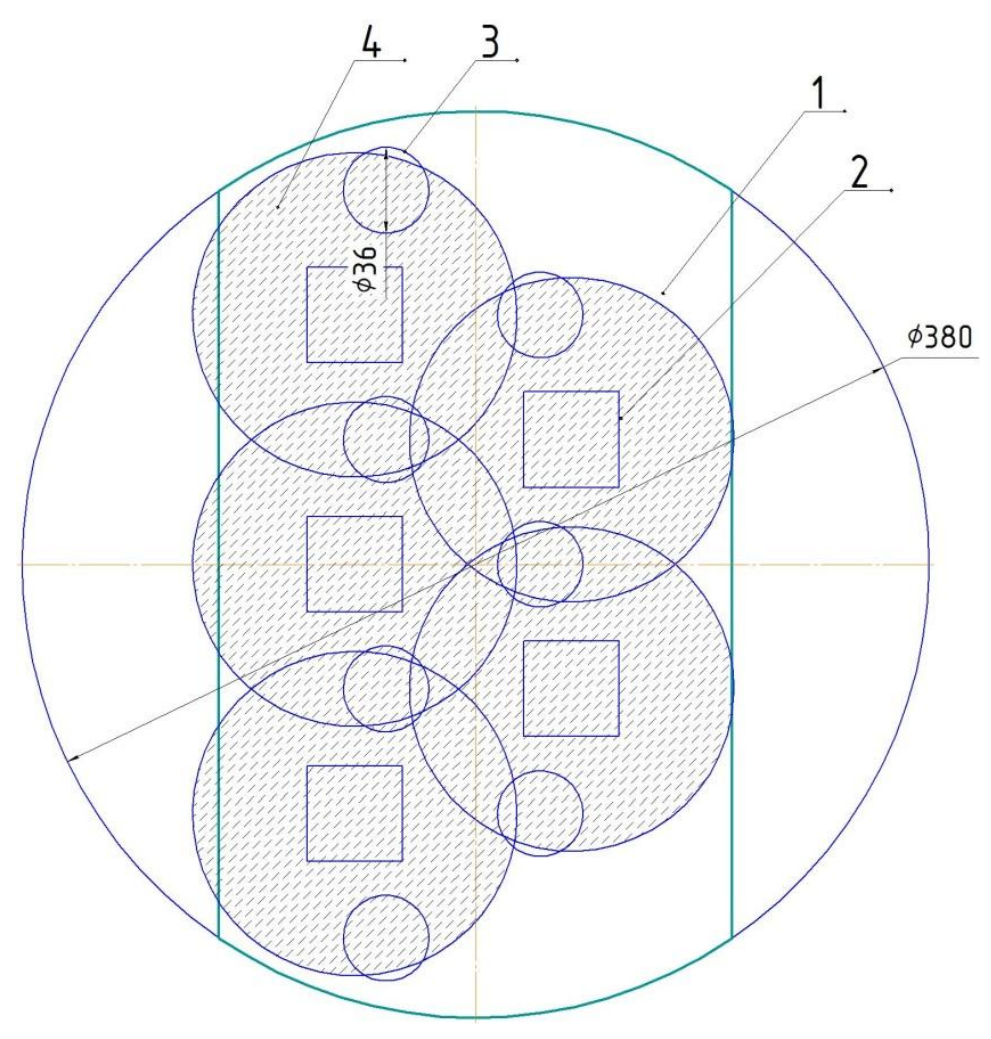

1 - полотно тарелки; 2 - ЭП; 3 - крепежные скобы;

4 - область термического воздействия

Рисунок 8. Локализация термоэлементов на колпачковой тарелке

Таблица 3. Данные по термическому воздействию ЭП на нагреваемую и охлаждаемую стороны тарелки

\begin{tabular}{|c|c|c|}
\hline Количество ЭП & $K_{t 1}, \%$ & $K_{t 2}, \%$ \\
\hline 5 & 74 & 47,8 \\
\hline
\end{tabular}

Площадь поверхности перекрытия зон нагрева от общей поверхности нагрева составила $8,3 \%$.

\section{Вывод}

Использование термоэлектрических преобразователей в колпачковых тарелках, согласно предложенной в данной статье конструкции, позволяет вводить дополнительную энергию в процесс ректификации путем создания температурного градиента, влияющего и на процесс конденсации, и на процесс парообразования. При внедрении ЭП в конструкцию тарелки в 
количестве 7 штук площади нагревания и охлаждения составляют 74,0% и 47,8 \% от свободной поверхности тарелки соответственно.

\section{Список используемых источников}

1. Хафизов Ф.Ш., Афанасенко В.Г., Хафизов Н.Ф. Кавитирование жидкой фазы как способ интенсификации массообменных процессов // Естественные и технические науки. 2007. № 4 (30). С. 267-268.

2. Rohman A.S., Rusmin P.H., Maulidda R., Hidayat E.M.I., Machbub C., Mahayana D. Modeling of the Mini Batch Distillation Column // International Journal on Electrical Engineering and Informatics. 2018. Vol. 10. Issue 2. pp. 350-368. DOI: 10.15676/ijeei.2018.10.2.11.

3. Grisales Díaz V.H., Olivar Tost G. Techno-Economic Analysis of Extraction-Based Separation Systems for Acetone, Butanol, and Ethanol Recovery and Purification // Bioresources and Bioprocessing. 2017. Vol. 4, Issue 1, pp. 4-12. URL: https://bioresourcesbioprocessing.springeropen.com /articles/10.1186/s40643-017-0142-z. (дата обращения: 05.05.2019). DOI: 10.1186/s40643-017-0142-Z.

4. Наумкин Е.А., Кузеев И.Р. Поверхность и поверхностные явления // Прикладная синергетика - II: матер. науч.практ. конф. Уфа, 2004. C. 171-179.

5. Долинский А.А., Ободович А.Н., Сидоренко В.В. Интенсификация аэрации и массопереноса в технологии очистки сточных вод за счет дискретно-импульсного ввода энергии // Теплофизика и аэромеханика. 2018. T. 25. № 4. С. 649-656.

6. Василишин М.С., Иванов О.С., Будаева В.В., Бычин Н.В., Золотухин В.Н., Гисматулина Ю.А. Оценка параметров диспергирования технической целлюлозы в роторно-пульсационном аппарате // Ползуновский вестник. 2016. № 4-1. С. 142-146. 
7. Васильев М.П., Абиев Р.Ш. Диспергирование капель масла в воде в пульсационном аппарате проточного типа // Известия СанктПетербургского государственного технологического института. 2014. № 23 (49). C. 66-68.

8. Юнусова Ю.Л. Интенсификация массообменных процессов нестационарными воздействиями // Матер. 45-й Междунар. науч.-техн. конф. молодых ученых, аспирантов и студентов. Уфа: Изд-во УГНТУ, 2018. C. 103-105.

9. Дубовкина И.А. Исследование свойств водно-спиртовых растворов при обработке методом дискретно-импульсного ввода энергии // Пищевая наука и технология. 2013. Т. 22. № 1. С. 64-66.

10. Драганов Б.Х., Борхаленко Ю.А. Основы концепции дискретноимпульсного ввода энергии // Труды Кубанского государственного аграрного университета. 2013. № 42. С. 147-151.

11. Bessarab O., Obodovich O., Sydorenko V. Intensification of Mass Transfer Processes in Gas-Liquid Media by Discrete-Pulse Energy Input Method // Ukranian Food Journal. 2016. Vol. 5. Issue 2. P. 368-375.

12. Tselen B., Stolitnia N. Influence of the Discrete-Pulse Input of Energy on ph of the Acidic Solution // International Scientific Journal «Internauka». 2017. Vol. 1. No. 28. pp. 72-77.

13. Боев Е.В., Афанасенко В.Г., Николаев Е.А., Иванов С.П. Повышение эффективности тепломассообменных насадок промышленных градирен // Газовая промышленность. 2010. No. 7 (648). С. 85-88.

14. Taqvi S.A., Tufa L.D., Muhadizir S. Optimization and Dynamics of Distillation Column Using Aspen Plus // Procedia Engineering. 2016. No. 148. pp. 978-984. URL: https://www.sciencedirect.com/science/article/pii /S1877705816309511?via\%3Dihub. DOI: 10.1016/j.proeng.2016.06.484. (дата обращения: 05.05.2019). 
15. Xiong W., Chen L., Liu F., Xu B. Multiple Model Identification for a High Purity Distillation Column Process Based on em Algorithm // Mathematical Problems in Engineering. 2014. Vol. 2014. No. 712682. 9 p. URL: https://www.hindawi.com/journals/mpe/2014/712682 (дата обращения: 05.05.2019). DOI: $10.1155 / 2014 / 712682$.

16. Афанасенко В.Г., Юнусова Ю.Л. Создание температурных неоднородностей с применением элемента Пельтье для интенсификации массообменных процессов нефтегазовой отрасли // Записки Горного института. 2019. Т. 235. С. 10-15. DOI: 10.31897/PMI.2019.1.10.

17. Harrson S. Santana, Geovanni B. Sanchez, Osvaldir P. Taranto Evaporation of Excess Alcohol in Biodiesel in a Microchannel Heat Exchanger with Peltier Module // Chemical Engineering Research and Design. 2017. No. 124. pp. 20-28.

18. Monfared B. Simulation of Solid-State Magnetocaloric Refrigeration Systems with Peltier Elements as Thermal Diodes // International Journal of Refrigeration.2017. No. 74. pp. 324-332.

19. Vries W., Theo H. van der Meer. Application of Peltier Thermal Diodes in a Magnetocaloric Heat Pump // Applied Thermal Engineering. 2017. No. 111. pp. 377-386.

20. Пат. 175743 РФ, МПК 51 В 01 D. Колпачковая тарелка с термоэлектрическими преобразователями / В.Г. Афанасенко, И.Р. Кузеев, М.И. Баязитов, П.А. Кулаков, Ю.Л. Юнусова. 2017111339, Заявлено 04.04.2017; Опубл. 18.12.2017. Бюл. № 35.

21. ОСТ 26-01-66-81. Тарелки колпачковые стальные колонных аппаратов. Параметры, конструкция и размеры. Харьков: УкрНИИхиммаш, 1986. $31 \mathrm{c}$. 


\section{References}

1. Khafizov F.Sh., Afanasenko V.G., Khafizov N.F. Kavitirovanie zhidkoi fazy kak sposob intensifikatsii massoobmennykh protsessov [Cavitation of a Liquid Phase as a Way of Intensification of a Mass Transfer Processes]. Estestvennye i tekhnicheskie nauki - Natural and Technical Sciences, 2007, No. 4 (30), pp. 267-268. [in Russian].

2. Rohman A.S., Rusmin P.H., Maulidda R., Hidayat E.M.I., Machbub C., Mahayana D. Modeling of the Mini Batch Distillation Column. International Journal on Electrical Engineering and Informatics, 2018, Vol. 10, Issue 2, pp. 350-368. DOI: 10.15676/ijeei.2018.10.2.11.

3. Grisales Díaz V.H., Olivar Tost G. Techno-Economic Analysis of Extraction-Based Separation Systems for Acetone, Butanol, and Ethanol Recovery and Purification. Bioresources and Bioprocessing, 2017, Vol. 4, Issue 1, pp. 4-12. Available at: https://bioresourcesbioprocessing.springeropen. com/articles/10.1186/s40643-017-0142-z (accessed 05.05.2019). DOI: 10.1186/s40643-017-0142-z.

4. Naumkin E.A., Kuzeev I.R. Poverkhnost' i poverkhnostnye yavleniya [Surface and Surface Phenomena]. Materialy nauchno-prakticheskoi konferentsii «Prikladnaya sinergetika - II» [Materials of Scientific-Practical Conference «Applied Synergetics - II»]. Ufa, 2004, pp. 171-179. [in Russian].

5. Dolinskii A.A., Obodovich A.N., Sidorenko V.V. Intensifikatsiya aeratsii $\mathrm{i}$ massoperenosa $\mathrm{v}$ tekhnologii ochistki stochnykh vod za schet diskretno-impul'snogo vvoda energii [Intensification of Aeration and Mass Transfer Process in Wastewater Treatment Technology due to Discrete Impulse Energy Input]. Teplofizika $i$ aeromekhanika - Thermophysics and Aeromechanics, 2018, Vol. 25, No. 4, pp. 649-656. [in Russian]. 
6. Vasilishin M.S., Ivanov O.S., Budaeva V.V., Bychin N.V., Zolotukhin V.N., Gismatulina Yu.A. Otsenka parametrov dispergirovaniya tekhnicheskoi tsellyulozy $\mathrm{v}$ rotorno-pul'satsionnom apparate [Estimation of Dispersion Parameters of Technological Cellulose in Rotary Pulsation Apparatus]. Izvestiya Sankt-Peterburgskogo gosudarstvennogo tekhnologicheskogo instituta - News of the St. Petersburg State Technological Institute, 2014, No. 23 (49), pp. 66-68. [in Russian].

7. Vasil'ev M.P., Abiev R.Sh. Dispergirovanie kapel' masla v vode v pul'satsionnom apparate protochnogo tipa [Dispersion of Oil Droplets in Water]. Izvestiya Sankt-Peterburgskogo gosudarstvennogo tekhnologicheskogo instituta - News of the St. Petersburg State Technological Institute, 2014, No. 23 (49), pp. 66-68. [in Russian].

8. Yunusova Yu.L. Intensifikatsiya massoobmennykh protsessov nestatsionarnymi vozdeistviyami [Intensification of Mass Transfer Processes by Non-Stationary Effects]. Materialy 45-i mezhdunarodnoi nauchno-tekhnicheskoi konferentsii molodykh uchenykh, aspirantov $i$ studentov [Materials of the International Scientific and Technical Conference of Young Scientists, Postgraduates and Students]. Ufa, USPTU Publ., 2018, pp. 103-105. [in Russian].

9. Dubovkina I.A. Issledovanie svoistv vodno-spirtovykh rastvorov pri obrabotke metodom diskretno-impul'snogo vvoda energii [The Study of the Properties of Water-Spirit Solutions after Application the Method of Discrete Impulse Energy Input]. Pishchevaya nauka i tekhnologiya - Food Science and Technology, 2013, Vol .22, No 1, pp.64-66. [in Russian].

10. Draganov B.Kh., Borkhalenko Yu.A. Osnovy kontseptsii diskretnoimpul'snogo vvoda energii [The Basics of the Concept of Discrete Impulse Energy Input]. Trudy Kubanskogo gosudarstvennogo agrarnogo universiteta Proceedings of the Kuban State Agrarian University, 2013, No. 42, pp. 147-151. [in Russian]. 
11. Bessarab O., Obodovich O., Sydorenko V. Intensification of Mass Transfer Processes in Gas-liquid Media by Discrete-Pulse Energy Input Method. Ukranian Food Journal, 2016, Vol. 5, Issue 2, pp. 368-375.

12. Tselen B., Stolitnia N. Influence of the Discrete-Pulse Input of Energy on PH of the Acidic Solution. International Scientific Journal «Internauka», 2017, Vol.1, No. 28, pp. 72-77.

13. Boev E.V., Afanasenko V.G., Nikolaev E.A., Ivanov S.P. Povyshenie effektivnosti teplomassoobmennykh nasadok promyshlennykh gradiren [Improving the Efficiency of Heat and Mass Transfer Nozzles of Industrial Cooling Towers]. Gazovaya promyshlennost' - Gas Industry, 2010, No. 7 (648), pp. 85-88. [in Russian].

14. Taqvi S.A., Tufa L.D., Muhadizir S. Optimization and Dynamics of Distillation Column Using Aspen Plus. Procedia Engineering, 2016, No. 148. pp. 978-984. Available at: https://www.sciencedirect.com/science /article/pii/S1877705816309511?via\%3Dihub (accessed 05.05.2019). DOI: 10.1016/j.proeng.2016.06.484.

15. Xiong W., Chen L., Liu F., Xu B. Multiple Model Identification for a High Purity Distillation Column Process Based on EM Algorithm. Mathematical Problems in Engineering, 2014, Vol. 2014, No. 712682, 9 p. Available at: https://www.hindawi.com/journals/mpe/2014/712682 (accessed 05.05.2019). DOI: $10.1155 / 2014 / 712682$.

16. Afanasenko V.G., Yunusova Yu.L. Sozdanie temperaturnykh neodnorodnostei $\mathrm{s}$ primeneniem elementa Pel't'e dlya intensifikatsii massoobmennykh protsessov neftegazovoi otrasli [Creation of Temperature Inhomogenities with the Use of Peltier Element for the Mass-Exchange Processes Intensification of the Oil and Gas Industry]. Zapiski Gornogo instituta - Journal of Mining Institute, 2019, Vol. 235, pp. 10-15. DOI: 10.31897/PMI.2019.1.10. [in Russian]. 
17. Harrson S. Santana, Geovanni B. Sanchez, Osvaldir P. Taranto Evaporation of Excess Alcohol in Biodiesel in a Microchannel Heat Exchanger with Peltier Module. Chemical Engineering Research and Design, 2017, No. 124 , pp. 20-28.

18. Monfared B. Simulation of Solid-State Magnetocaloric Refrigeration Systems with Peltier Elements as Thermal Diodes. International Journal of Refrigeration, 2017, No. 74, pp. 324-332.

19. Vries W., Theo H. van der Meer. Application of Peltier Thermal Diodes in a Magnetocaloric Heat Pump. Applied Thermal Engineering, 2017, No. 111, pp. 377-386.

20. Afanasenko V.G., Kuzeev I.R., Bayazitov M.I., Kulakov P.A., Yunusova Yu.L. Kolpachkovaya tarelka $s$ termoelektricheskimi preobrazovatelyami [Cap Plate with Thermoelectric Converters]. Patent RF, No. 175743, 2017. [in Russian].

21. OST 26-01-66-86 Tarelki kolpachkovye stal'nye kolonnykh apparatov. Parametry, konstruktsiya $i$ razmery [OST 26-01-66-86. Steel Cap Plates of Column Apparatus. Parameters, Design and Dimensions], Khar'kov, UkrNIIkhimmash, 1986. 31 p. [in Russian].

\section{Сведения об авторах}

\section{About the author}

Афанасенко Виталий Геннадьевич, канд. техн. наук, доцент кафедры «Механика и конструирование машин», УГНТУ, г. Уфа, Российская федерация

Vitaliy G. Afanasenko, Candidate of Engineering Sciences, Assistant Professor of Mechanics and Design of Machines Department, USPTU, Ufa, Russian Federation

e-mail: afanasenko.v.g@yandex.ru 
Юнусова Юлия Ленаровна, аспирант кафедры «Технологические машины и оборудование», УГНТУ, г. Уфа, Российская федерация

Julia L. Yunusova, Post-graduate Student of Process Machinery and Equipment Department, USPTU, Ufa, Russian Federation

e-mail: nedra.ugntu@gmail.com

Хузиев Вильнар Файзуллович, магистрант кафедры «Технологические машины и оборудование», УГНТУ, г. Уфа, Российская федерация

Vilnar F. Khuziev, Undergraduate Student of Process Machinery and Equipment Department, USPTU, Ufa, Russian Federation

e-mail: khuziev1305@mail.ru

Яковлев Виталий Александрович, инженер Центра научнотехнического творчества механического факультета, УГНТУ, г. Уфа, Российская федерация

Vitaliy A. Yakovlev, Engineer of Scientific and Technical Creativity Center of Mechanical Faculty, USPTU, Ufa, Russian Federation

e-mail: jakovleffvitaly@yandex.ru 